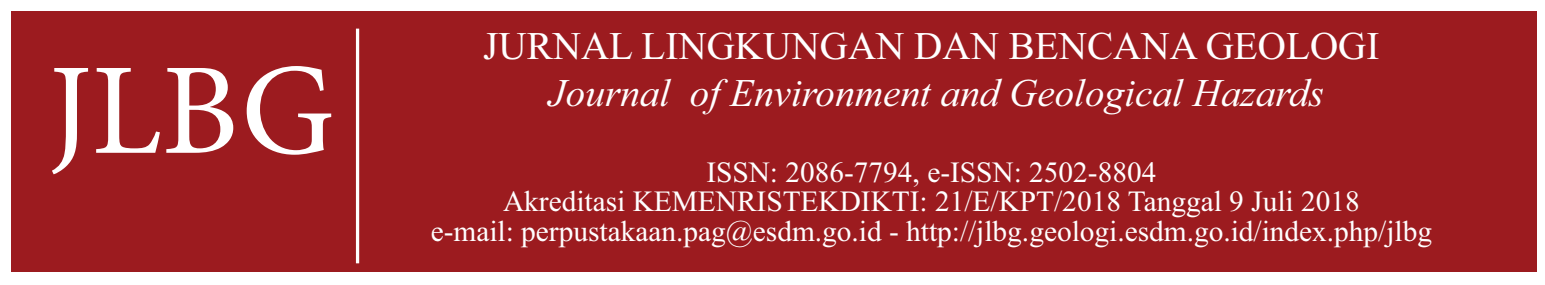

\title{
Tingkat Konsolidasi Penurunan Lahan Berdasarkan Metode Asaoka di Lahan Area 1B Blok J di Lokasi JIIPE, Manyar, Gresik, Jawa Timur
}

\author{
Land Consolidation Rate Based on Asaoka Method \\ in Area 1 B Block J Land at JIIPE, Manyar, Gresik, East Java
}

\author{
Anto Kadyanto, Hendarmawan, dan Bombom Rachmat Suganda \\ Program Studi Teknik Geologi, Fakultas Teknik Geologi, Universitas Padjadjaran \\ Jln. Raya Bandung-Sumedang Km. 21, Jatinangor 45363, Indonesia \\ e-mail: anto17001@mail.unpad.ac.id \\ Naskah diterima 16 Januari 2020, selesai direvisi 29 Agustus 2020, dan disetujui 30 Agustus 2020
}

\begin{abstract}
ABSTRAK
Tingkat konsolidasi pada lahan lunak dapat ditentukan dengan menggunakan Metode Asaoka (1978). Metode ini dipilih karena penerapannya yang sederhana dan memiliki tingkat akurasi yang dapat diandalkan, merujuk kepada hasil penelitian-penelitian lain. Observasi penurunan lahan dilakukan di Area 1B Blok J, di lokasi JIIPE, Manyar, Gresik Jawa Timur. Metode Asaoka merupakan suatu teknik untuk memperkirakan penurunan tanah dengan menggunakan grafik curve fitting, yaitu proses data-smoothing, pendekatan terhadap kecenderungan data dalam bentuk persamaan model matematika; biasanya digunakan untuk keperluan interpolasi. Dengan cara ini, kebutuhan akan data lapangan dan data pendukung seperti: data laboratorium berupa tekanan air pori, panjang aliran air, koefisien konsolidasi dan regangan maksimum tanah, tidak diperlukan. Validasi data dilakukan dengan memperbandingkan tingkat konsolidasi yang dihasilkan berdasarkan pengamatan dari metode Asaoka dengan desain teknis engineering. Hasil penelitian menunjukkan bahwa tingkat konsolidasi yang dihitung dari observasi data menggunakan metode Asaoka adalah 96.93\% yang terbukti lebih besar daripada desain teknis engineering (95\%).
\end{abstract}

Kata kunci: kawasan industri, metode Asaoka, tanah lunak, tingkat pemadatan

\section{ABSTRACT}

Consolidation rate on soft soil can be determined using the Asaoka Method (1978). In this study, the method was chosen because of its simple application and has a reliable level of accuracy, referring to the results from other studies. Observation of ground settlement was taken from Area 1 B Block J located in JIIPE, Manyar, Gresik, East Java. The Asaoka method is a technique for estimating ground settlement using curve-fitting graph: a process of data-smoothing, approach of data trends in the form of mathematical equations; usually used for interpolation purposes. With this technique, the needs for field data and supporting data such as laboratory data in the form of pore pressure, water flow length, consolidations coefficient, and maximum soil strain, are not required. Data validation is done by comparing the degree of consolidations results based on Asaoka Method observation with the technical design of engineering. The result shows that the consolidation degree calculated from Asaoka Method observational data was $96.93 \%$, which is proven greater than the technical engineering design (95\%).

Keywords: industrial estate, Asaoka method, soft soil, consolidation degree

\section{PENDAHULUAN}

Perhitungan penurunan lahan pada tanah lunak dengan menggunakan penyaliran vertikal (vertical drain) dan dikombinasikan dengan me- tode pembebanan sangatlah penting, sehingga penentuan waktu untuk menghilangkan pembebanan dan dimulainya konstruksi struktur/ gedung di atas lahan tersebut dapat diketahui. 
Tingkat konsolidasi adalah salah satu parameter geoteknik yang sangat penting untuk menghadapi masalah ini. Ada beberapa metode untuk mengevaluasi tingkat konsolidasi pada lahan lunak yaitu menggunakan hasil observasi yang dikenal sebagai Asaoka, Hyperbolic, Moden, dan sebagainya. Setiap metode memiliki keunggulan dan kelemahan masing-masing. Untuk menentukan tingkat konsolidasi dalam jangka waktu tertentu menggunakan hasil observasi penurunan dengan menggunakan Metode Asaoka dianggap sebagai metode yang umum, paling sederhana serta dapat diandalkan. Penelitian dilakukan berdasarkan acuan pada penurunan permukaan dan karakteristik material timbunan.

Tujuan utama penelitian ini adalah menerapkan Metode Asaoka untuk menentukan tingkat konsolidasi tanah lunak. Dalam kasus ini, hasil pengamatan settlement plate dikumpulkan dari projek penurunan lahan di Kawasan Industri JIIPE. Validasi data juga dilakukan dengan membandingkan tingkat konsolidasi yang ditentukan dari Metode Asaoka dengan desain Teknis Engineering. Lokasi penelitian terdapat pada Lahan Area 1B Blok J di Lokasi Jiipe, Manyar, Gresik, Jawa Timur (Gambar 1).

Peta Geologi Regional Surabaya - Sapulu (Supandjono drr, 1992) (Gambar 2), menunjukkan bahwa lapisan bagian bawah JIIPE terletak di atas endapan aluvial kuarter (Qa) dengan topografi berupa perbukitan rendah yang terbentuk dalam Formasi Madura sekitar $6 \mathrm{~km}$ ke baratdaya. Endapan aluvial umumnya terdiri dari lempung, pasir dan cangkang kerang di beberapa tempat, kerikil dan kerakal. Pengamatan rinci menyatakan bahwa material permukaan alami biasanya mengandung sedimen berbutir halus dalam endapan aluvial, yang juga tanah terpadatkan, mengandung sedikit lanau dan lapisan pasir lepas, menutupi lempung yang getas atau sangat getas serta pasir yang menengah hingga sangat padat.

Tanah terdiri dari partikel padatan dan rongga yang bisa terisi oleh air (jenuh), sedikit air atau udara (tanpa air). Ketika tanah tidak mengandung air atau sedikit air, tanah tersebut menjadi padat dan terdeformasi. Selanjutnya partikel tanah akan saling merapat dan menyebabkan menurunnya porositas sehingga tanah menjadi padat. Untuk tanah yang jenuh, rongga-rongganya terisi oleh air maka ketika ada pembebanan, partikel tanah akan saling merapat dan mendorong air di dalam rongga tertekan keluar melalui rekahan menuju ke permukaan dan selanjutnya menghilang; proses inilah yang dinamakan sebagai konsolidasi (Asaoka, 1978). Untuk memantau proses konsolidasi tanah

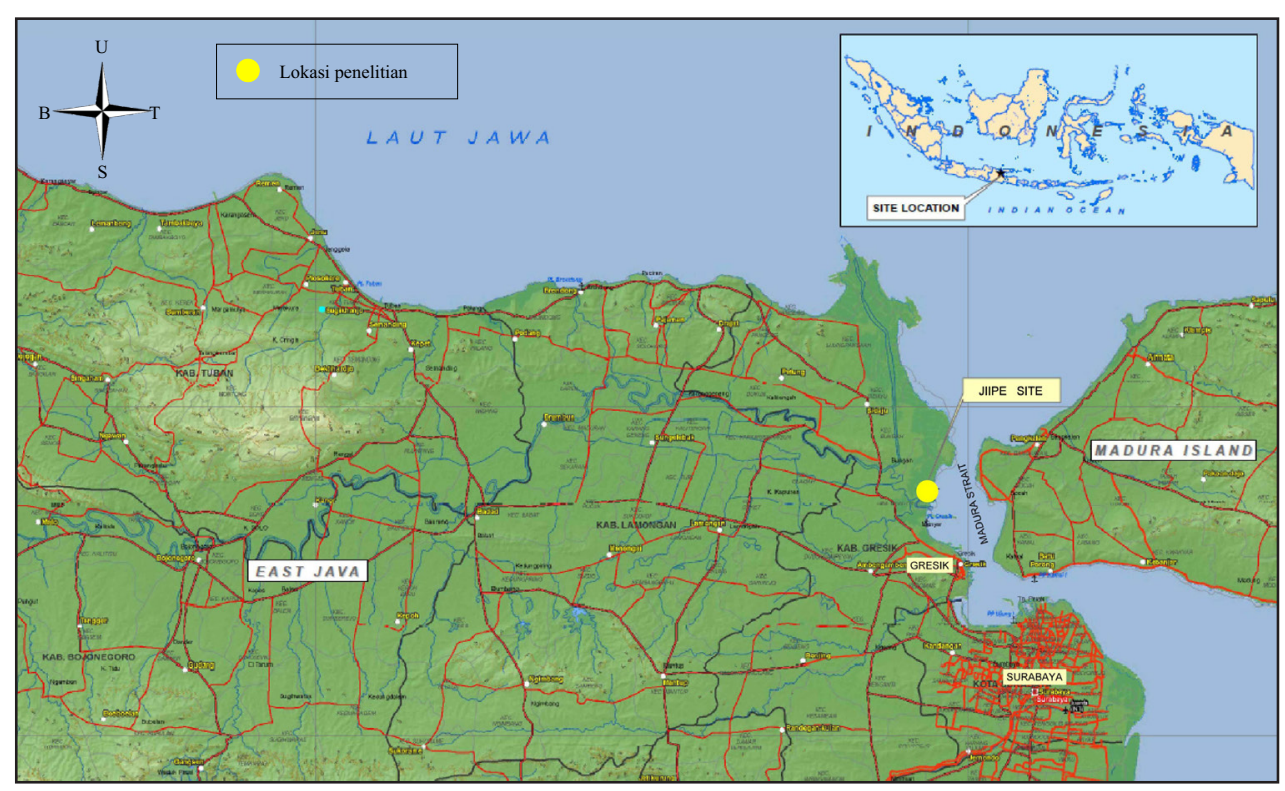

Gambar 1. Lokasi Penelitian Lahan Area 1B Blok J di Lokasi JIIPE, Manyar, Gresik, Jawa Timur. 


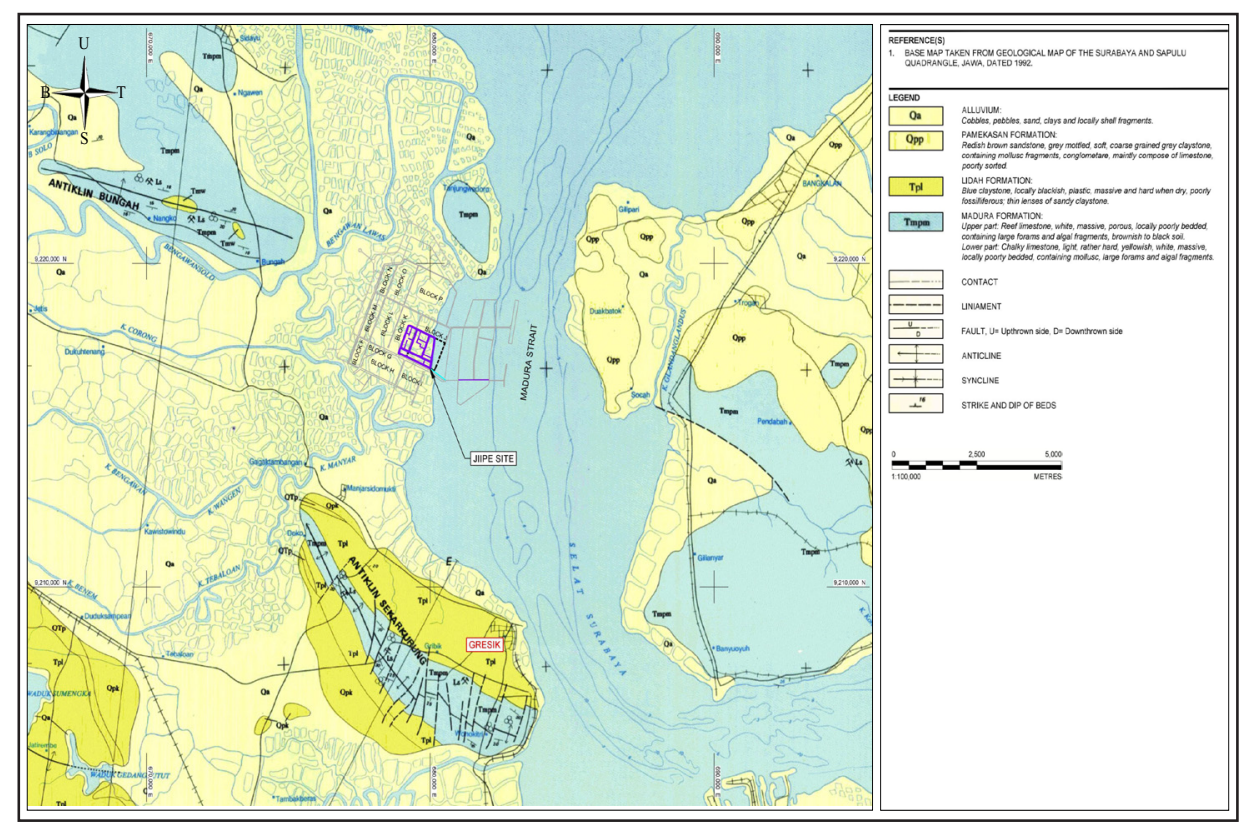

Gambar 2. Peta Geologi Regional Lembar Surabaya - Sapulu (Supandjono drr, 1992).

lunak yang menggunakan penyaliran vertikal dan kombinasi dengan metode pembebanan, digunakan settlement plate.

\section{METODE PENELITIAN}

Penelitian ini menggunakan Metode Asaoka yaitu pengamatan settlement plate untuk menentukan tingkat konsolidasi dan memperkirakan settlement akhir dari tanah lunak yang menggunakan penyaliran vertikal dan dikombinasikan dengan metode pembebanan. Asaoka telah membuktikan bahwa jika kita membagi kurva pengamatan settlement menjadi multi-point dengan interval waktu yang sama ketika kita menggambar grafik dengan sumbu horizontal $\mathrm{S}_{\mathrm{i}-1}$ dan sumbu vertikal $\mathrm{S}_{\mathrm{i}}$, maka semua titik berada pada garis lurus. Ini akan divalidasi ketika pembebanan konstan, sesuai dengan pembebanan maksimum. Settlement akhir akan memotong garis yang menghubungkan semua titik dengan garis $-45^{\circ}$ (Gambar 3). Berdasarkan teori konsolidasi, untuk pembebanan konstan, hubungan kurva ini merupakan garis lurus, yang membantu kita menghitung perbedaan parameter konsolidasi terhadap kondisi aktual, termasuk settlement utama (pada titik perpotongan dari garis lurus dan garis median).

Pada kenyataannya, teori settlement adalah sebagai berikut:

$$
S_{i}=S_{\infty} \cdot\left(1-\frac{8}{\pi^{2}} \cdot e^{(-C . t)}\right)
$$

Dimana:

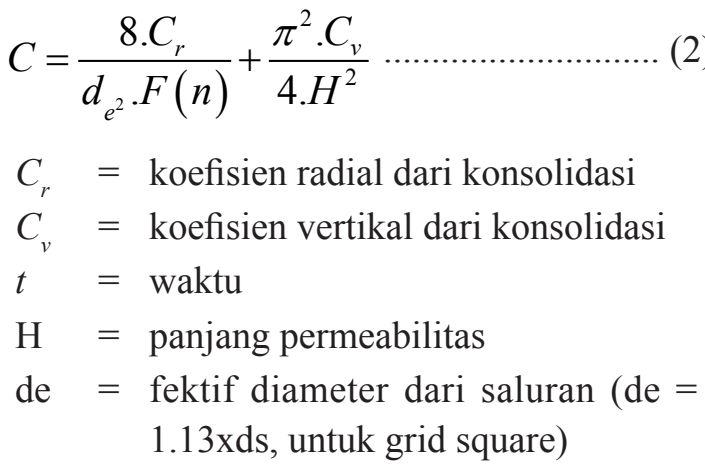

$F(n)=\frac{n^{2}}{n^{2}-1} \cdot \ln (n)-\frac{3 \cdot n^{2}-1}{4 \cdot n^{2}}$

$n=d_{s} / d_{w}$

dimana:

$d_{s}=$ jarak antara PVD

$d_{w}=$ diameter ekivalen dari saluran 


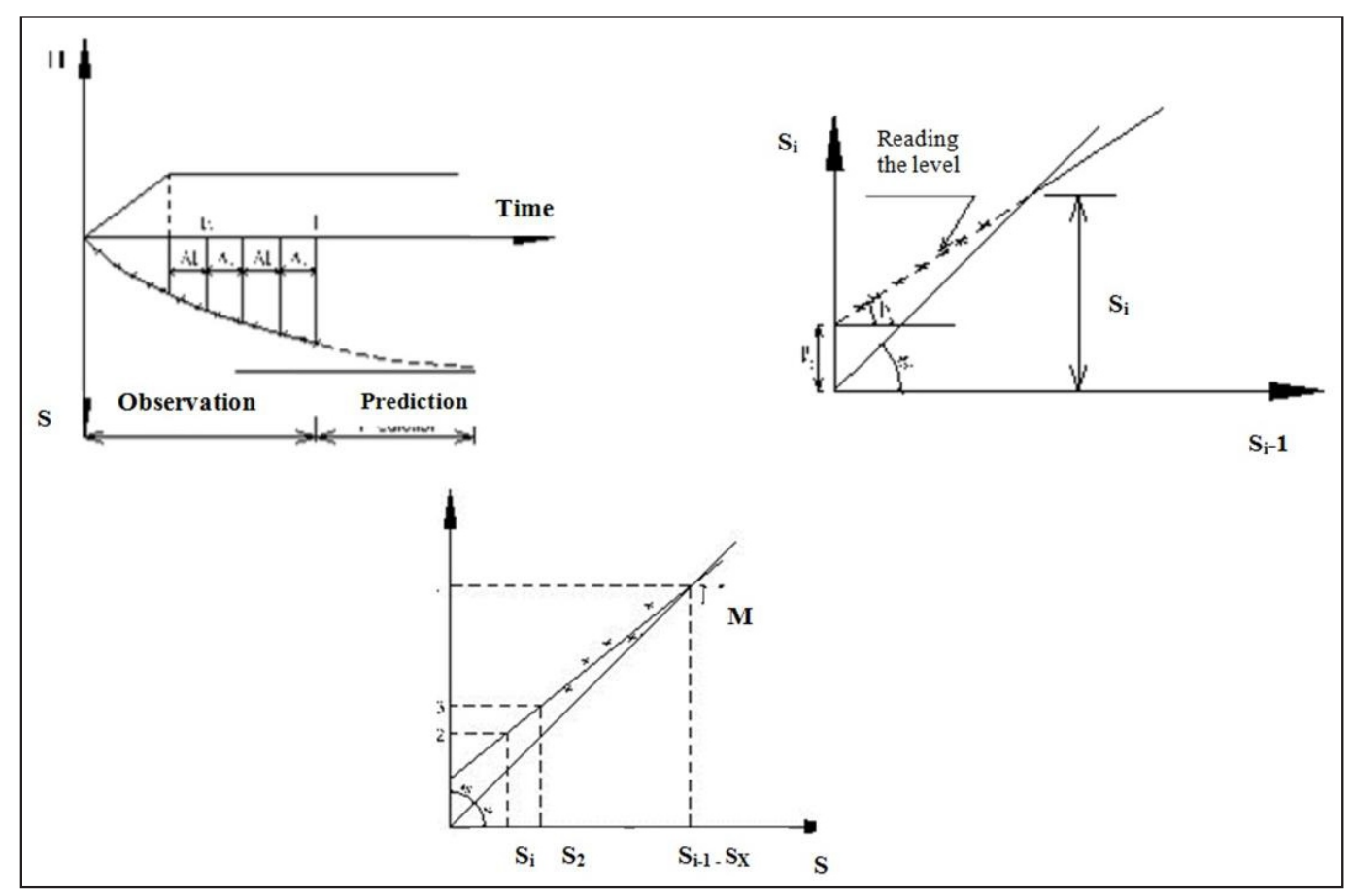

Gambar 3. Analisa settlement berdasarkan Metode Asaoka (Asaoka, 1978).

Untuk menentukan $\Delta \mathrm{t}$, kita memiliki:

$$
\begin{aligned}
& S_{i}=S_{\infty} \cdot\left(1-\frac{8}{\pi^{2}} \cdot e^{(-C \cdot(t+\Delta t)}\right)=S_{\infty} \cdot\left(1-e^{(-C . \Delta t)}\right)+e^{(-C . \Delta t)} \cdot S_{i-1} \\
& \rightarrow S_{i}=\beta_{o}+\beta_{s} \cdot S_{i-1}
\end{aligned}
$$

Garis hubungan di atas adalah garis lurus dengan kemiringan $\beta$ s yang terkait dengan koefisien C. Ketika kemiringan garis ini ditentukan, maka koefisien konsolidasi bisa ditentukan. Selain itu, settlement pada periode $\mathrm{t}$ dapat dikalkulasi dengan hanya membaca dari settlement diperpotongan antara garis hubungan dan garis median.

Maka settlement akhir:

$$
S_{\infty}=\frac{\beta_{o}}{1-\beta_{s}}
$$

Proses konsolidasi dibagi menjadi 2 (dua) tahap, yaitu: (1) konsolidasi primer, saat air dalam rongga menghilang, rongga mengecil dan tanah menjadi padat; (2) konsolidasi sekunder, ketika rongga sudah menghilang dan partikel tanah terus bergerak menuju ke padat permanen.

$$
U_{t}=\frac{S_{t}}{S_{\infty}}
$$

Dimana:

$$
\begin{aligned}
\mathrm{S}_{\mathrm{t}}= & \text { settlement dalam waktu } \mathrm{t} \\
\mathrm{S}_{\infty}= & \text { settlement akhir (settlement utama) } \\
& \text { yang merupakan settlement maksimum } \\
& \text { pada saat pembebanan konstan. }
\end{aligned}
$$

Untuk proses pematangan tanah lunak menggunakan saluran vertikal yang dikombinasikan dengan metode pembebanan, settlement aktual di lapangan pada periode tertentu $t$ ditentukan dengan menggunakan plat penurunan (settlement plate). Settlement plate ini berukuran 800 x 800 $\mathrm{mm}$, dengan tebal $300 \mathrm{~mm}$, terikat kuat dengan tiang pengukur, yang terbuat dari besi dengan diameter lebih kecil dari tabung penutupnya (tanah tidak boleh kontak dengan pipa pengukurnya); tabung pipa tidak terikat pada settlement plate. Pipa pengukur berdiameter $50 \mathrm{~m}$; pipa pengukur dan tabung pipa dibagi menjadi beberapa bagian, setiap bagian memiliki panjang $0.5-1 \mathrm{~m}$, agar memudahkan penyambungan ketika terjadi penambahan ketinggian (Gambar 4). 


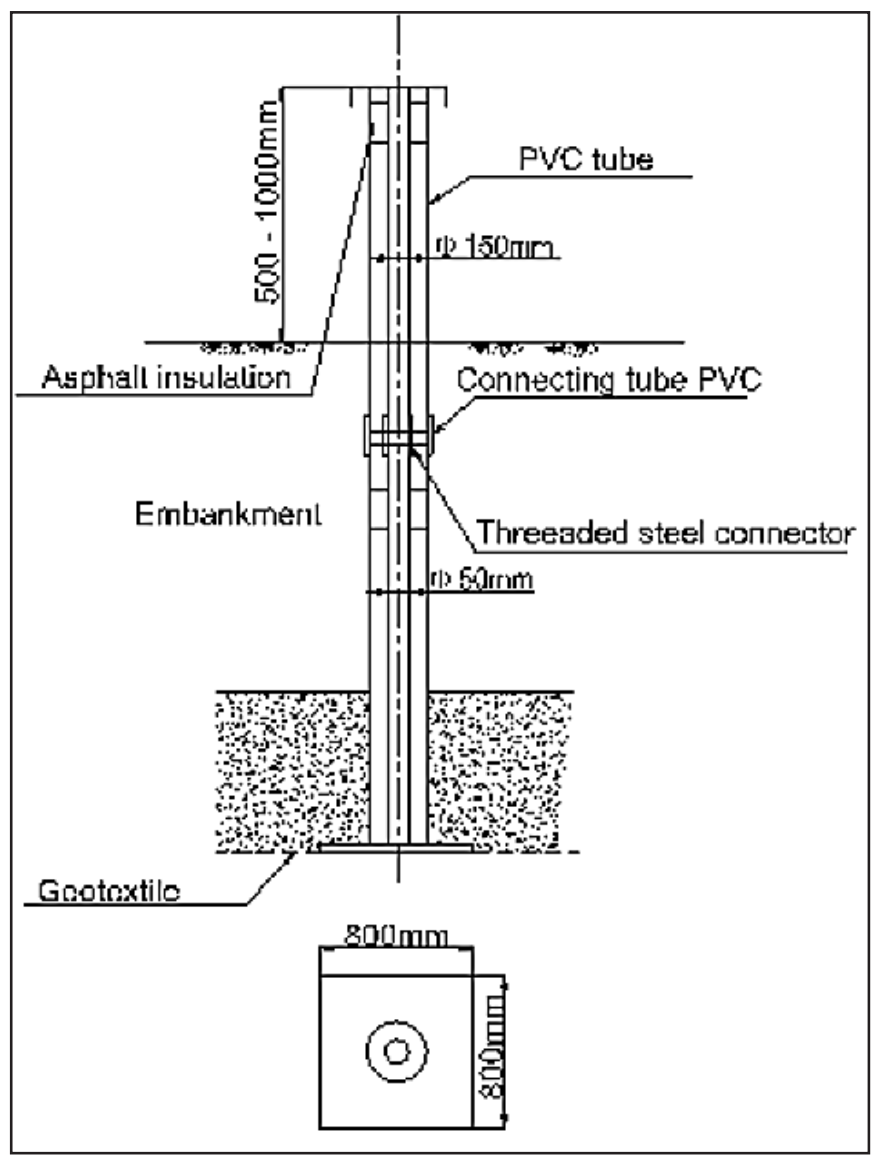

Gambar 4. Konfigurasi Settlement Plate.

Settlement plate dipasang pada level awal penimbunan. Jika terdapat lapisan pasir keras, maka plat diposisikan di tempat itu. Jika ada lapisan yang getas di atas tanah lunak, maka plat akan ditempatkan pada posisi tersebut, atau bisa juga jika ada lapisan geotextile, plat juga bisa diposisikan pada lapisan geotextile. Jika settlement plate harus dipasang pada tanah lunak, maka 30 $\mathrm{cm}$ tanah lunak harus digali dan diganti dengan pasir, setelah itu barulah plat bisa diposisikan pada lapisan pasir tersebut. Settlement plate harus berada dalam kondisi yang baik sampai pekerjaan selesai.

Secara umum, pengamatan pemapanan permukaan dapat dilakukan dengan metode geodesi konvensional, yaitu dengan mesin level dan tiang level (Gambar 5). Elevasi ujung pipa dari settlement plate ditentukan berdasarkan elevasi pengukuran, dengan melakukan leveling teknis dari benchmark terhadap settlement plate. Pe- nurunan adalah perbedaan antara elevasi awal dan elevasi akhir ketika dilakukan pengukuran dalam periode waktu tertentu.

Pemantauan settlement dilakukan segera setiap hari sesudah settlement plate dipasang dan selama pekerjaan penimbunan dan proses pembebanan; jika pekerjaan penimbunan dibagi menjadi beberapa tahap, harus dipantau juga setiap hari pada setiap tahapan. Ketika ada yang tidak sesuai, maka diperlukan penerapan pengukuran off-cycle. Penyesuaian data settlement harus diterapkan segera untuk pengambilan keputusan terhadap keberlanjutan konstruksi dan kecepatan pembebanan.

Studi kasus penurunan lahan terjadi di Area 1B blok J, Kawasan Industri JIIPE. Penurunan lahan dirancang untuk memenuh syarat kriteria kepadatan 95\% MDD dengan akhir kekuatan konsolidasi 90\% (Gambar 6). Luas area 1B adalah sekitar $85,415 \mathrm{~m}^{2}$, dengan profil geoteknik adalah sebagai berikut: $339,1 \mathrm{~m}$ x 252,0 m, 


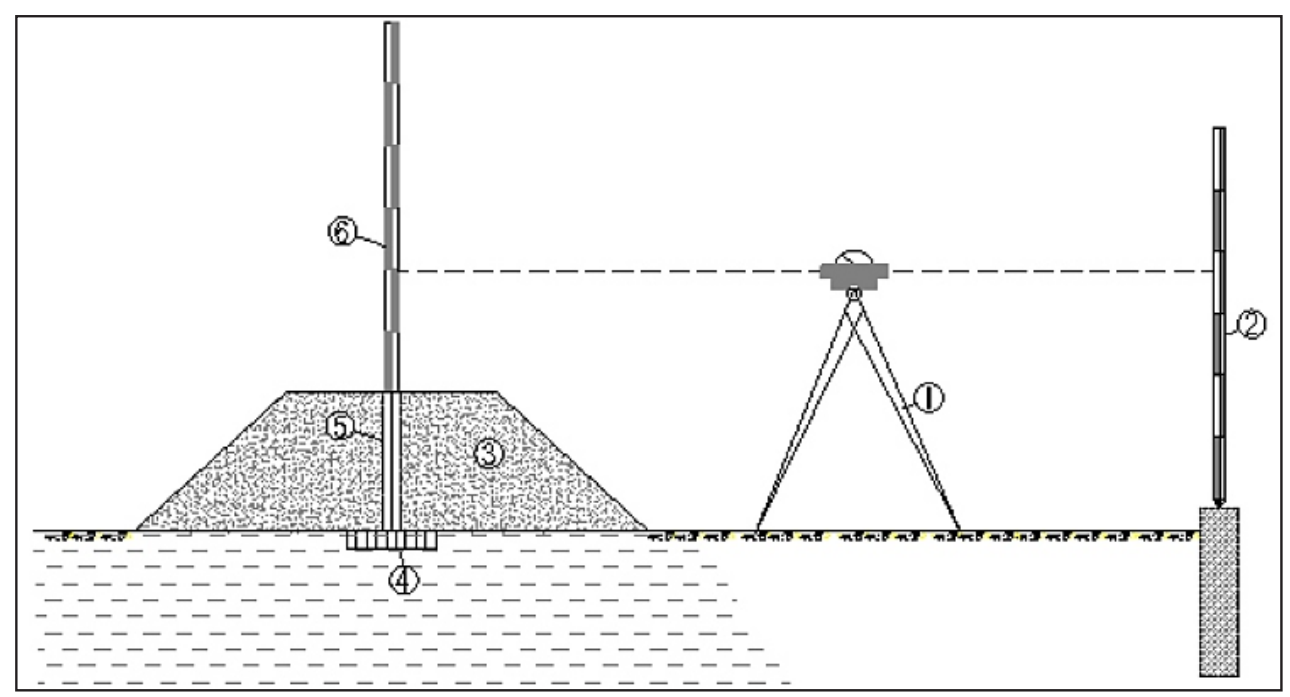

Gambar 5. Penampang settlement permukaan (1 - mesin level; 2 - Benchmark; 3 - Urugan; 4 - settlement plate; 5 - Tabung plastik; 6 - Tiang level).

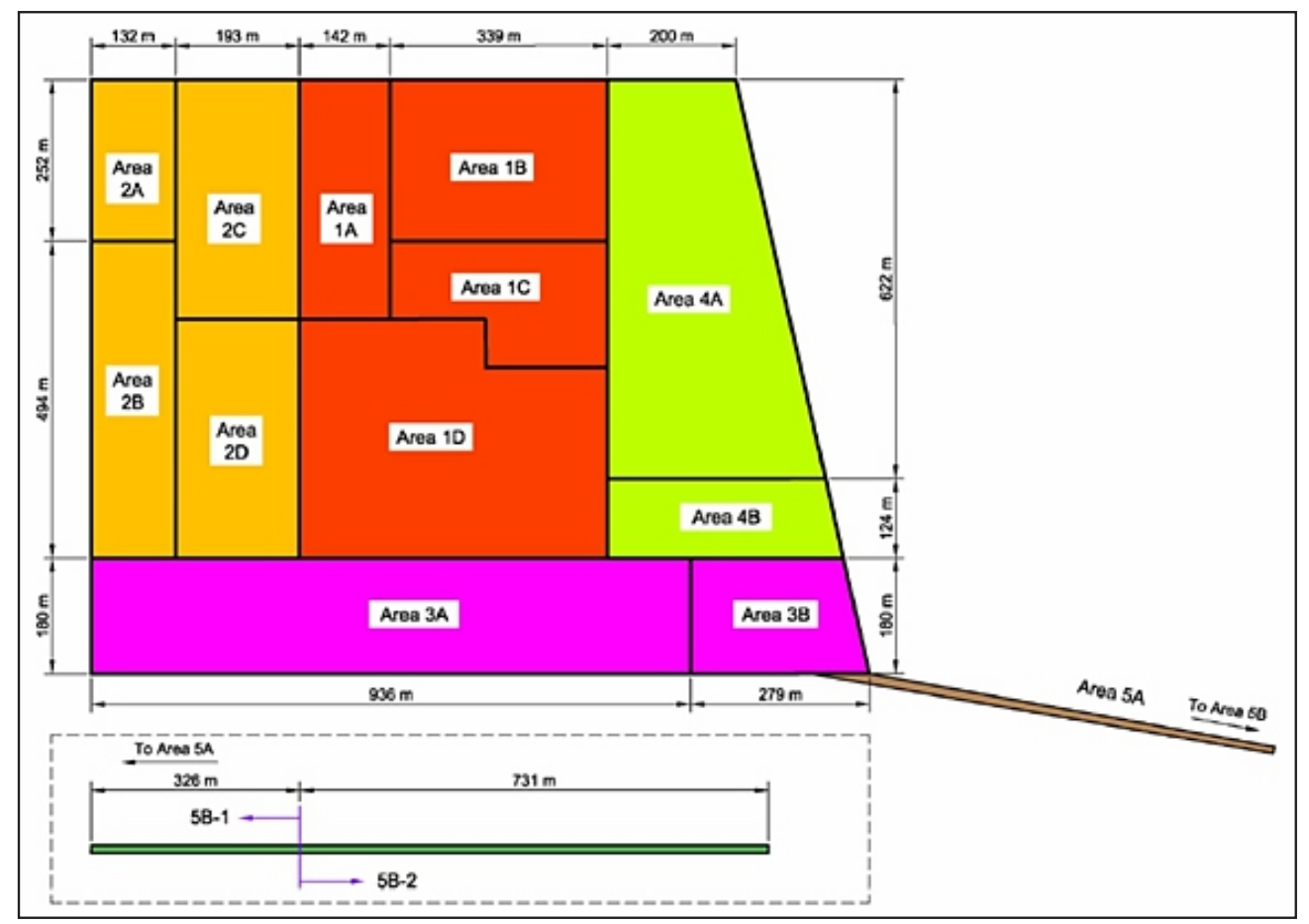

Gambar 6. Denah lokasi Pabrik di Lokasi JIIPE, Manyar, Gresik.

kedalaman urugan berkisar antara15,3 - 24,4 m; Nilai SPT-N (N60 untuk lempung/lanau dan $\mathrm{N} 1,60$ untuk pasir/gravel) untuk zona di bawah permukaan di area $1 \mathrm{~B}$ yaitu SPT-N $=0-10$ (pasir), dan SPT-N = 1 - 6 (lempung), menunjukkan area ini terdiri dari material pasir sangat lepas hingga menengah padat, dan lempung lunak sampai getas.
Di area 1, yang merupakan lokasi pengamatan, terdapat 9 titik settlement plate, yaitu: SP-03, SP-04, SP-05, SP-18, SP-19, SP-20, SP-25, SP-26, dan SP-27. Dalam hal ini, SP-03 diambil sebagai salah satu contoh titik pengamatan. Penampang melintang dari setiap lapisan timbunan dapat diilustrasikan dalam gambar di bawah ini (Gambar 7). 


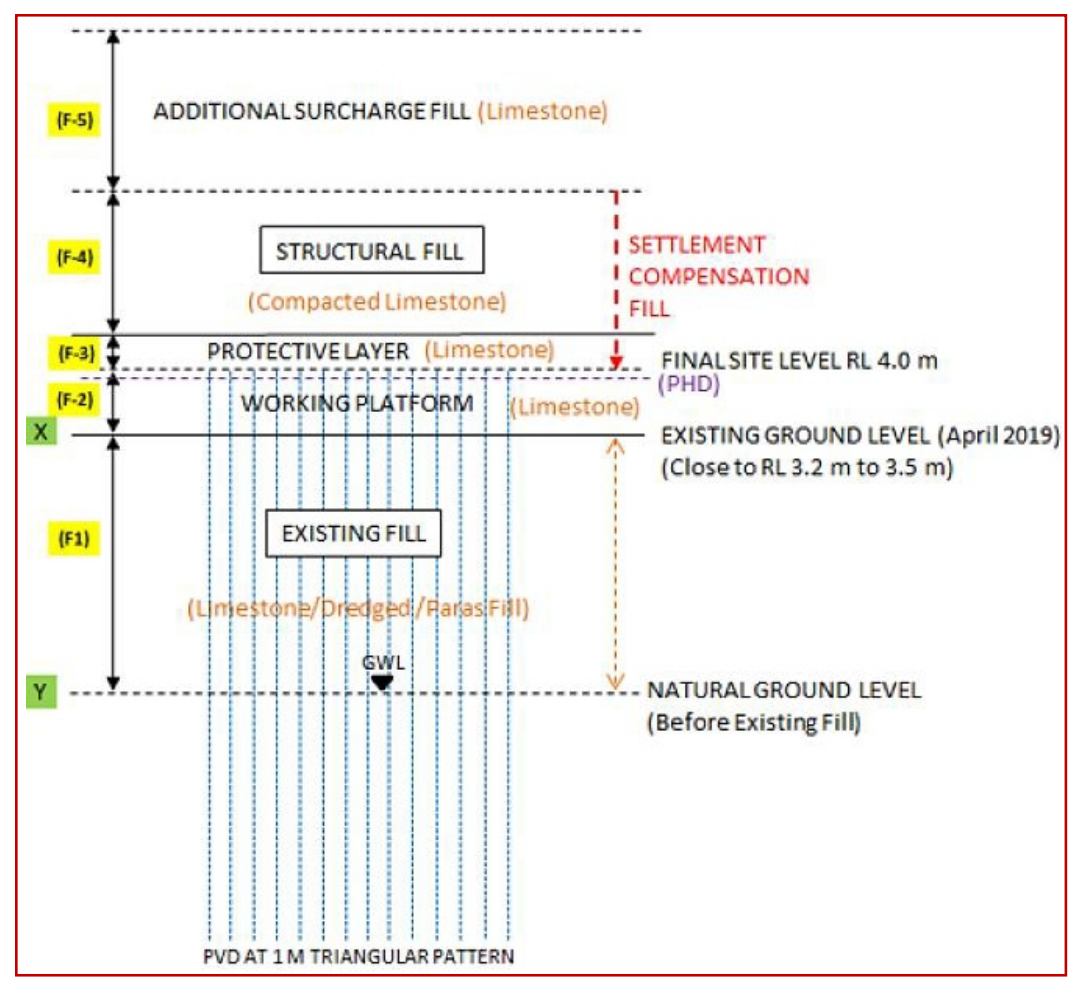

Gambar 7. Ilustrasi penampang melintang setiap lapisan timbunan.

\section{HASIL DAN PEMBAHASAN}

Dari hasil pengamatan, ditemukan bahwa untuk pertama kalinya, setelah timbunan mencapai 3 lapis, penurunan terjadi sangat cepat. Namun, ketika mencapai di 200 hari pemantauan, penurunan terlihat melambat dan mengindikasikan timbunan tanah mulai mencapai tahap stabil. Hasil pengukuran pada 60 hari pertama pengamatan terlihat pada grafik di bawah ini (Gambar 8).

Hasil pengamatan penurunan final/settlement final (Sf) selanjutnya diperhitungkan dengan menggunakan dua data dari hasil pembacaan settlement plate yaitu data awal penimbunan dan data akhir penimbunan. Hasil perhitungan nilai settlement final ditampilkan pada Tabel 1 .

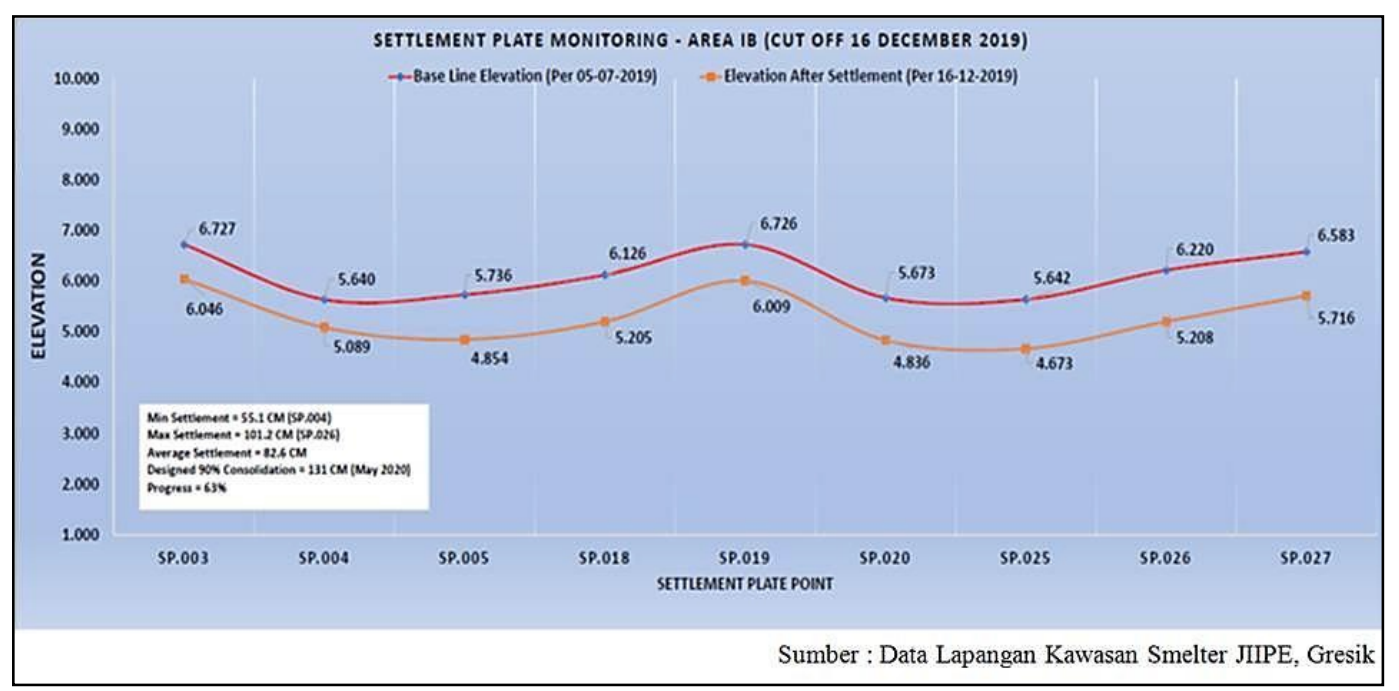

Gambar 8. Grafik Penurunan Berdasarkan Pemantauan Settlement Plate Selama 60 hari. 
Tabel 1. Perbandingan nilai penurunan total dari awal penimbunan dan akhir penimbunan

\begin{tabular}{|c|c|c|}
\hline No. SP & $\begin{array}{c}\text { Penurunan final dari data } \\
\text { awal penimbunan (mm) }\end{array}$ & $\begin{array}{c}\text { Penurunan final dari data } \\
\text { akhir penimbunan (mm) }\end{array}$ \\
\hline SP-003 & 2165 & 1949 \\
SP-004 & 2094 & 1885 \\
SP-005 & 2610 & 2349 \\
SP-018 & 2318 & 2086 \\
SP-019 & 2051 & 1845 \\
SP-020 & 2390 & 2151 \\
SP-025 & 2433 & 2190 \\
SP-026 & 2558 & 2302 \\
SP-027 & 2301 & 2071 \\
\hline
\end{tabular}

Dari tabel di atas dapat dilihat bahwa hasil Sf yang diperoleh dari data awal penimbunan lebih besar dari hasil Sf yang diperoleh dari data akhir penimbunan. Perhitungan Sf dapat dilakukan secara matematis dari persamaan garis regresi linear yang terdapat pada grafik Asaoka (Gambar 9).

Contoh Persamaan Garis pada SP-03 (perhitungan yang sama digunakan untuk settlement plate yang lainnya):

$\mathrm{Y}=0,8908 \mathrm{X}+236,4$

$\mathrm{X}=0,8908 \mathrm{X}+236,4$

$X-0,8908 X=236,4$
$0,1092 \mathrm{X}=236,4$

$X=236,4 / 0,1092$

$\mathrm{X}=2165$

$\mathrm{Sf}=2165 \mathrm{~mm} \sim 2,165 \mathrm{~m}$

Untuk membandingkan nilai Sf yang diperoleh dari grafik Asaoka, kita harus cermat dalam menentukan data penimbunan yang digunakan sebagai acuan, karena hasilnya akan berbeda. Hasil perhitungan Sf yang diperoleh dengan menggunakan data awal penimbunan akan lebih besar nilainya jika hanya dengan menggunakan data akhir penimbunan.

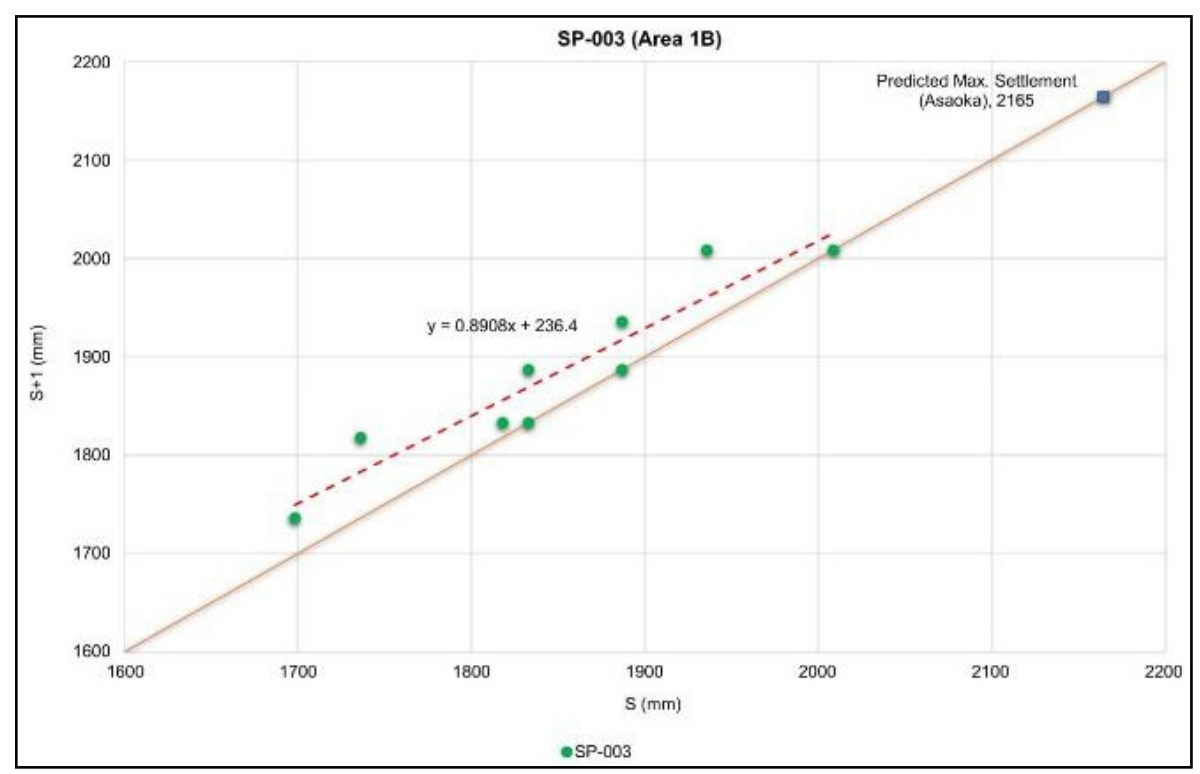

Gambar 9. Grafik Asaoka (SP-03). 
Grafik Asaoka berfungsi untuk memprediksi penurunan akhir maksimum settlement plate (SP) dengan bersumber dari data aktual lapangan. Dalam grafik tersebut, garis regresi linear (garis merah putus) yang dibentuk berdasarkan interpolasi data pembacaan settlement plate di lapangan. Untuk mendapatkan penurunan akhir maksimum, Asaoka membuat garis bantu diagonal $45^{\circ}$ agar terjadi perpotongan antara garis regresi linear dengan garis bantu diagonal. Pertemuan atau perpotongan antara kedua garis tersebut merupakan angka prediksi penurunan akhir maksimum, yang bernilai 2,165 m.

Analisa waktu untuk mencapai derajat konsolidasi $(\mathrm{U})>90 \%$ dari data awal penimbunan dan dari data akhir penimbunan menggunakan Metode Asaoka. Dalam perhitungan ini data yang digunakan adalah data nilai settlement final dari perhitungan sebelumnya. Kemudian kita menggunakan persamaan di bawah untuk mendapatkan nilai S. Sebagai contoh kita gunakan nilai Sf pada SP-03.

Nilai S pada data awalpenimbunan:

$\mathrm{S}=\mathrm{U} * \mathrm{Sf}$

$\mathrm{S}=0.9 * 2165$

$\mathrm{S}=1,95 \mathrm{~m}$

Untuk $\mathrm{S}$ pada data akhirpenimbunan:

$\mathrm{S}=\mathrm{U} * \mathrm{Sf}$

$\mathrm{S}=0.9 * 1949$

$\mathrm{S}=1,75 \mathrm{~m}$
Hasil dan waktu untuk mencapai derajat konsolidasi (U) $>90 \%$ dapat dilihat pada Tabel 2 .

Untuk mencapai derajat konsolidasi (U) $\geq$ 90\% dengan mengggunakan nilai Sf pada data awal penimbunan pada SP-03, SP-04, SP-05, SP-18, SP-19, SP-20, SP-25, SP-26 dan SP-27, waktu yang diperlukan untuk mencapai derajat konsolidasi $90 \%$ tidak ditemukan pada pembacaan settlement plate, karena telah memasuki proses pemotongan lapisan atas timbunan. Untuk menentukan tercapainya derajat konsolidasi tersebut, maka digunakan data waktu pembacaan penurunan total terakhir pada settlement plate. Pada Table 3 ditunjukkan penurunan akhir dan tingkat konsolidasi dengan perhitungan metode Asaoka lebih besar dari pada desain teknis engineering, dalam waktu pengamatan yang sama (60 hari).

Tabel 3. Perbandingan Desain Teknis vs. Metode Asaoka

\begin{tabular}{|ccc|}
\hline Parameter & $\begin{array}{c}\text { Desain Teknis } \\
\text { Engineering }\end{array}$ & $\begin{array}{c}\text { Metode } \\
\text { Asaoka }\end{array}$ \\
\hline Penurunan Akhir & $131 \mathrm{~cm}$ & $174.857 \mathrm{~cm}$ \\
Tingkat Konsolidasi & $95 \%$ & $96,93 \%$ \\
Waktu & 60 hari & 60 hari \\
\hline
\end{tabular}

Tabel 2. Perbandingan hasil vs. Waktu mencapai derajat Konsolidasi

\begin{tabular}{|ccccccc|}
\hline & \multicolumn{2}{c}{ Settlement Final } & \multicolumn{2}{c}{$\begin{array}{c}\text { Penurunan Pada } \\
(\mathbf{U})=\mathbf{9 0 \%}\end{array}$} & \multicolumn{2}{c|}{$\begin{array}{c}\text { Waktu Mencapai } \\
\mathbf{( U )}=\mathbf{9 0 \%}\end{array}$} \\
\cline { 2 - 7 } No. SP & $\begin{array}{c}\text { Data awal } \\
\text { penimbunan } \\
(\mathbf{m m})\end{array}$ & $\begin{array}{c}\text { Data akhir } \\
\text { penimbunan } \\
(\mathbf{m m})\end{array}$ & $\begin{array}{c}\text { Data awal } \\
\text { penimbunan } \\
(\mathbf{m m})\end{array}$ & $\begin{array}{c}\text { Data akhir } \\
\text { penimbunan } \\
(\mathbf{m m})\end{array}$ & $\begin{array}{c}\text { Design } \\
\text { Awal } \\
\text { (hari) }\end{array}$ & $\begin{array}{c}\text { Aktual } \\
\text { Lapangan } \\
\text { (hari) }\end{array}$ \\
\hline SP-03 & 2165 & 1949 & 1949 & 1754 & 180 & 109 \\
SP-04 & 2094 & 1885 & 1885 & 1697 & 180 & 109 \\
SP-05 & 2610 & 2349 & 2349 & 2114 & 180 & 109 \\
SP-18 & 2318 & 2086 & 2086 & 1877 & 180 & 109 \\
SP-19 & 2051 & 1845 & 1845 & 1661 & 180 & 109 \\
SP-20 & 2390 & 2151 & 2151 & 1936 & 180 & 109 \\
SP-25 & 2433 & 2190 & 2190 & 1971 & 180 & 109 \\
SP-26 & 2558 & 2302 & 2302 & 2072 & 180 & 109 \\
SP-27 & 2301 & 2071 & 2071 & 1864 & 180 & 109 \\
\hline
\end{tabular}




\section{KESIMPULAN}

Dari hasil penelitian ini dapat disimpulkan bahwa: Metode Asaoka sangat efektif untuk memperkirakan hasil akhir penurunan tanah dan tingkat konsolidasi. Hasil pengamatan settlement plate menunjukkan penurunan signifikan pada perbaikan tanah sehingga diperoleh hasil yang diharapkan. Perbaikan tanah lunak dengan menggunakan metode penyaliran vertikal (vertical drain) sangat efektif karena mempercepat proses pemadatan tanah lunak. Pemadatan tanah dapat dicapai dalam 60 hari dengan tingkat konsolidasi $96,93 \%$, lebih besar dari pada perkiraan desain teknis engineering (95\%).

\section{UCAPAN TERIMA KASIH}

Penulis mengucapkan terimakasih kepada management PT. Freeport Indonesia yang telah memberikan izin menggunakan data sebagai pelengkap paper ini serta para manajer dan staf PT. Freeport Indonesia yang sudah memberikan dukungan dan sumbang saran dalam penyelesaian paper ini.

\section{DAFTAR PUSTAKA}

Asaoka, A., 1978. Observational Procedure of Settlement Prediction, Soils and Foundation, No.4.

Hiep Van Le, et al., 2017. Analysis of Consolidation Degree Using Settlement Observation Result an Asaoka Method; A Case Study of Route KM 94+340 - KM 94+ 440" of Hanoi - Haipong Highway Construction Project.
International Journal of Civil Engineering and Technology (IJCIET), Vol 8, Issue 11, Nopember 2017, pp. 91 -100, Article ID: IJCIET_08_11_010. ISSN Print"0976-6308 and ISSN online: 0976-6316.

Indonesia Freeport Smelter Project Phase 2 Detailed Geotechnical Investigation JIIPE site, Gresik, East Java, Geotechnical Engineering Report.,2019. Golder Associates (PT Geotechnical and Environmental Service Indonesia), Jakarta.

J.B. Supandjono drr, 1992. Peta Geologi Regional Surabaya - Sapulu, Jawa Timur, skala 1:100.000, P3G, Bandung, Jawa Barat.

Nawir, H., Apoji, D.,Fatimatuzahro, R., Pambudji, M.D., 2012.Prediksi Penurunan Tanah Menggunakan Prosedur Asaoka Studi Kasus: Timbunan di Bontang, Kalimatan Timur. Jurnal Teknik Sipil, Rekayasa Sipil, vol. 19, pp 133-148.

Rizky Hidayat, 2016. Pengaruh Pemadatan Tanah di bawah Standar MDD 95\% terhadap Perilaku Tanah Ekspansif di Kawasan Lippo Cikarang Bekasi, Jawa Barat. Program Studi Teknik Sipil S-1, FakultasTeknologi dan Kejuruan, Universitas Pendidikan Indonesia. Siregar, Muhammad Imam Ma'arif, drr, 2017. mengenai Estimasi Parameter Kompaksi Berdasarkan Nilai Klasifikasi Tanah Pada Projek Jalan Raya, Laboratorium Mekanika Tanah Departemen Teknik Sipil, USU.

Tan T, Inoue T, Lee S., 1991.Hyperbolic method for consolidation analysis. Journal of Geotechnical Engineering 1991;117(11):172337. 